\title{
Ethnic discrimination in China's internet job board labor market
}

Margaret Maurer-Fazio

Correspondence:

mmaurer@bates.edu

276 Pettengill Hall, Bates College, 4

Andrews Road, Lewiston, Maine

04240, USA

\begin{abstract}
We conduct a large-scale field experiment to investigate how Chinese firms respond to Internet job board applications from ethnic minority and Han applicants. We signal ethnicity by using names that are typically Han Chinese and distinctively Mongolian, Tibetan, and Uighur. We find significant differences in callback rates by ethnicity. These differences vary systematically across ethnic groups. Not all firms discriminate-approximately half treat all candidates equally. State-owned firms are much less likely than others to discriminate in favor of Han candidates and both state- and foreign-owned firms are significantly more likely to treat candidates equally than do privately owned firms.
\end{abstract}

JEL Codes: J71, J23, J15, O52, P25

Keywords: Chinese firms, Hiring, Discrimination, Ethnicity, Internet job boards, Resume correspondence audit study

\section{Introduction and context}

Laborers shall not be discriminated against in employment due to their nationality, race, sex, or religious belief.

Article 12: People's Republic of China Labor Law (2012)

Workers enjoy the right to employment on equal footing and to choice of jobs on their own initiative in accordance with law. In seeking employment, workers shall not be subject to discrimination because of their ethnic backgrounds, race, gender, religious beliefs, etc.

Article 3: People's Republic of China Law on Promotion of Employment (2012)

There is a nascent but growing academic literature focused on how China's ethnic minorities have fared in China's economic transition. Researchers have addressed disparities in rural and urban income (Gustafsson \& Li 2003) (Ding \& Li 2009), rural poverty (Gustafsson \& Ding 2008), occupational attainment and job segregation (Hannum \& Xie 1998), job search, hiring, and promotion (Hasmath 2011, 2012b; Howell and Fan 2011), and labor force participation (Maurer-Fazio, Hughes, \& Zhang 2007, 2010). Although the specific research questions asked, and methodologies applied, have varied considerably, most of the above papers find that China's ethnic minorities have not fared well in comparison to the majority Han during China's transition to a market economy. However, some of the differences in Han and minority wellbeing are

(c) 2012 Maurer-Fazio; licensee Springer. This is an Open Access article distributed under the terms of the Creative Commons Attribution License (http://creativecommons.org/licenses/by/2.0), which permits unrestricted use, distribution, and reproduction in any medium, provided the original work is properly cited. 
attributable to differences in education levels and residential location. It is particularly important to sort out whether and to what extent observed differences in the labor market outcomes of majority Han and ethnic minority participants are due to differences in Han and ethnic minority attributes (differences in productive characteristics) or to the treatment of those attributes, that is, to discrimination. A number of the above mentioned studies apply decomposition techniques to try to discover what share of the differences in labor market outcomes can be "explained" by differences in productive characteristics. The "unexplained" differences, that is, the residual differences in income or labor force participation or occupational attainment are then often attributed to discrimination but may in reality be due to model misspecification, omitted variables, and/ or unobservable aspects of productivity differences.

This study takes a more direct approach to studying discrimination. Using a resume audit approach we directly measure the extent of ethnic discrimination in the hiring practices of Chinese firms. The resume audit methodology allows us to strictly control aspects of job candidates' productivity experimentally while varying their ethnicity (as denoted by ethnically differentiated names) ${ }^{1}$. Resume audit studies have been used to study discrimination in a wide variety of country and labor market contexts ${ }^{2}$. This, however, is the first application of a resume audit study to test for discrimination against ethnic minorities in the hiring practices of Chinese firms.

In our resume audit study, conducted in the summer of 2011, we submitted 21,592 applications to 10,796 positions advertised on Internet job boards in 6 Chinese cities. The positions varied over three types of occupations. We randomly paired Han applications with one of three minorities with ethnically distinct names: Mongolian, Uighur, and Tibetan. We found significant discrimination against each of the minorities except in Hohhot and Urumqi-- two autonomous minority areas. Discrimination was less prevalent in tight labor markets. Although candidates of each minority group experienced discrimination, not all firms discriminated. Close to half the firms treated their paired applicants equally. State-owned firms were significantly more likely to treat candidates equally and much less likely to discriminate in favor of Han candidates than private firms.

In the following sections of this paper, we first provide some context on China's ethnic minorities and then review the literature that examines how they have fared during China's economic transformation to a market economy. We then briefly review the literature on ethnicity-focused resume audit studies and go on to describe our own experimental design. We then present the analysis of our results-first from the perspective of individual applicants and then from the perspective of the firms selecting applicants for callbacks. We summarize our findings in the concluding section.

\section{China's ethnic minorities}

According to China's 2010 population census, ethnic minorities constitute $8.4 \%$ of the Chinese population (112 million people). We use the term ethnic minority here to refer to members of the 55 minority groups who, along with the Han majority, make up the country's 56 officially recognized ethnic groups. Many of China's ethnic minority people (75\%) dwell in regions that are specially designated as autonomous ethnic minority areas (Information Office of the State Council of the People's Republic of China 1999: 15). However, the Han also comprise a significant proportion of these regions' populations ${ }^{3}$. These officially 
designated minority autonomous areas, which take up $63.9 \%$ of China's land area, are rich in natural resources and for the most part located in the politically sensitive border regions of southwest and northwest China (SEAC. State Ethnic Affairs Committee 2003). Given that official economic data on China's minority peoples is usually published by autonomous region rather than by ethnic group ${ }^{4}$, it is quite difficult to get a sense of the relative economic well being of China's minority peoples. Even though overall economic indicators show a rising standard of living in ethnic minority regions (Mackerras 2003: 56-76), these improvements have not kept pace with developments in the national economy. Sautman (2010) reports that the material gap between Han and minority areas continues to widen.

According to a recent government White Paper:

The Constitution stipulates, "The state does its utmost to promote the common prosperity of all ethnic groups in the country." The Law on Regional Ethnic Autonomy stipulates that it is a legal obligation of the higher-level state organs to help the minority areas accelerate their development. (Information Office of the State Council of the People's Republic of China 2009).

With its implementation of the Western Development Plan in 2000, the Chinese state began to address the economic development of minority areas in earnest ${ }^{5}$. The Plan integrated investment in large-scale development and infrastructure projects in western China with preferential allocation of resources to autonomous minority areas (Information Office of the State Council 2009). This development strategy rapidly accelerated GDP growth in China's western minority regions. It also led to increased ethnic tensions in particular areas (Bhattacharji 2012). For example, Xinjiang's economy has grown at double-digit rates. The rising number of jobs has led to substantial in-migration of Han to the area. This has caused Uighur residents to fear they are being excluded from the good jobs and to believe that the Han migrants are grabbing these jobs as well as other resources (The Economist 2011), which in turn has led to a rising ethno-religious consciousness (Hasmath 2012a, 2012b). There are reports of rising resentment over job discrimination (Bequelin 2009, Fallows 2009) ${ }^{6}$.

According to Sautman (2010), there are two main types of preferential policies aimed at China's ethnic minorities: subsidies to minority areas and affirmative action for minority people. The extent of the latter varies by particular minority. The government's preferential policies include preferential treatment in school admissions, hiring and promotion. Sautman (2010) points out that the preferential policies were designed at a time when the state sector was the dominant sector in the Chinese economy and that few of these policies apply to the private sector, which has grown in importance rapidly throughout the reform period. Whether, and to what extent, these policies are implemented are important questions, as is the question of whether the policies are differentially applied in state-sector and privately owned firms.

While ethnic minorities in western China resent the in-migration of substantial numbers of Han, there is also rising Han resentment of minorities who are viewed as receiving unwarranted advantages (Sautman 2010). This long-smoldering resentment, burst into flame after protests in Lhasa in 2008 and Urumqi in 2009 turned into violent riots that resulted in many casualties and fatalities.

Although there are competing claims of unfair/unwarranted labor market advantages and disadvantages being made by some Han and some minority job seekers, others feel 
that employers don't care much about ethnic status. Zhao (2008) reports that a survey of university graduates of the Inner Mongolia Industrial University found that most respondents believed employers cared much more about candidates' abilities than their ethnicity. Of those who responded that they believed that employers cared about ethnic minority status, some felt minority language skills were valued and advantageous in searching for jobs and others felt that particular work units/employers discriminated against minorities.

In this paper we directly investigate how minorities are treated relative to the Han in a rapidly expanding segment of China's urban labor markets-Internet job boards. We focus on just one aspect of labor market experience-whether, and to what extent, firms take ethnicity into account in making their hiring decisions. More specifically, we focus on whether firms discriminate on the basis ethnicity when making decisions about which applicants to interview-a critical first step in the hiring process.

\section{Literature review-ethnic minorities in China's economic reform}

There is a growing interest in understanding how China's economic transition of the last three decades has affected ethnic minority people. Gustafsson and Li (2003) find that the gaps in rural income between the Han and ethnic minorities widened from 19.2\% to 35.9\% between 1988 and 1995 (based on survey data from 19 provinces). They decompose the income differentials and attribute the lion's share to differences in endowments-particularly to location, given that China's minorities are clustered in provinces with low per capita GDP. Gustaffson and Ding (2008) build on this earlier work to focus on poverty. Based on a 2002 survey of 22 provinces, they argue that poverty in rural China has a very strong spatial dimension-that ethnic minorities have higher rates of both persistent and temporary poverty because minorities are concentrated in western China, home to most of China's poor. They report that that ethnic minority status has little independent effect in explaining poverty and, rather, that factors such as the education level of the household head, village mean income, and whether the village is located in a mountainous area are much more important factors than ethnicity. Hannum and Xie (1998) employ population census data to examine the effects of market reform on differences in occupational attainment of Xinjiang's (mainly Turkic) minorities in comparison to the Han. They find that the ethnic gap in occupational attainment between the Han and the minorities widened between the 1982 and 1990 censuses. They also conclude that the gap is not directly attributable to discrimination but rather to growing differences in productive characteristics, in particular, to an increased gap in the educational attainment between the Han and the minorities and a presumed strengthening of the relationship between educational attainment and higher-status occupations.

In contrast to the above-mentioned studies, when Ding and Li (2009) analyze differences in income determination for Hui (minority) and Han urban residents in Ningxia based on survey data gathered in 2007 and decompose the differences in earnings into treatment and endowment effects, they find that the treatment effects are more important than endowment effects in explaining the incomes differences. They point out, however, that the treatment effects do not always favor the Han. In their study, the returns to education are somewhat higher for the Han than the Hui, while the returns to experience are higher for the Hui than the Han. They find that state ownership of 
the workplace favors the Han. Maurer-Fazio, Hughes, and Zhang (2007) find that minorities were affected more adversely than the Han by reductions in urban sector employment and exited the labor force more rapidly than Han. Maurer-Fazio, Hughes, and Zhang (2010) estimate urban labor force participation rates of women. They focus on the experience of six ethnic minorities and the Han and find sizable differences. In pair-wise comparisons between Han and ethnic women, they find that the treatment of women's characteristics, whether in the market or socially, tends to increase the Han advantage in labor force participation, while the levels of those characteristics tend to reduce the Han advantage. After conducting interviews and analyzing census data, Hasmath (2011) argues that in practice ethnic minorities are disadvantaged relative to the Han in terms of hiring and promotions, particularly for well-paying, high-skill jobs.

The economic literature to date suggests that China's ethnic minorities are not faring particularly well, relative to the Han, in terms of labor market outcomes. However, there is no clear consensus as to whether the differences in income, poverty, occupational attainment, and related factors are due to differences in residential location and productive characteristics or to discriminatory treatment.

\section{Review of the literature-ethnicity-focused resume audit studies}

The resume audit methodology is well suited for measuring discrimination in hiring. ${ }^{7}$ Resume audit studies combine the advantages of controlled experiments and realistic field settings. In a resume audit study, sets of resumes are created for fictitious applicants. They are carefully crafted to ensure that candidates will appear, on paper, to be equally productive with similar work and educational histories. The researchers then control a particular attribute under study such as gender or age (or, in our case, ethnicity). Discrimination is measured by the differences in the rates of callbacks for interviews received by individuals whose applications typically vary only in terms of the attribute under study.

Resume audit studies have been used to investigate the role of ethnicity in a number of different national settings. Bertrand and Mullainathan (2004) study race in US labor markets by randomly assigning White-sounding and African American-sounding names to resumes and submitting those resumes to positions advertised in Boston and Chicago newspapers. They find that candidates with White names receive 50\% more callbacks than candidates with African American names. Siddique (2008) explores caste-based discrimination in India's white-collar labor market. She finds that low-caste applicants (signaled by typical low-caste names) need to put in 20\% more applications than high-cast applicants to get the same number of callbacks for interviews. She finds that high-caste applicants received even higher callback rates when the recruiting is carried out by men or by Hindu recruiters. Kaas and Manger (2011) develop a study of German firms' responses to applications for student internships from applicants with Turkish- and German-sounding names. They are particularly careful to create resumes that do not conflate immigration status with ethnicity. The applicants they create with Turkish-sounding names "are" German citizens who were both born and educated in Germany and whose mother tongue is German. The only difference between these applicants and the others lies in the ethnicity of their names. They find, all else equal, that the applicants with German sounding names get 14\% more callbacks than those with Turkish-sounding names, in general, but $24 \%$ more callbacks from small firms. 
However, they are able to eliminate the differences in callback rates by including letters of reference that contain favorable information about the personality of the applicant. They take this to indicate that the discrimination is statistical in nature, since supplying more information could eliminate it.

Carlsson and Rooth (2007), Bursell (2007), and Carlsson (2010) conduct resume audit studies in Sweden using names that sounded Swedish and African or Arab or Middle Eastern. Booth, Leigh, and Varganova (2011); and Oreopoulos and Dechief (2011) conduct resume audit studies in Australia and Canada using names that sounded in the first case: Anglo-Saxon and Indigenous, Chinese, and Middle Eastern; and in the second case: English, Indian, or Chinese. Each of these studies finds significant discrimination against those with foreign-sounding names. The Bursell, Carlsson, and Oreopoulos and Dechief studies control for differences in language abilities and/or country of education. Booth, Leigh, and Varganova signal assimilation into Australian society by giving each of their applicants an Australian high school education. Each of these five studies incorporates a range of occupations and attempts to use differential callback rates by occupation to either help sort out or speculate about the sources and types of discrimination.

We have carefully searched the English and Chinese literature and have not found any reports of resume audit studies focused on China's labor markets. However, Guang and Kong (2010) carried out an audit study of gender and rural status discrimination in Beijing's labor market in the summer of 2004. They trained student actors to apply in person for advertised positions at local Beijing job fairs. Their male and female applicants were assigned roles as either Beijing residents or applicants from outside Beijing with rural household registrations. These applicants audited 81 employers and found that rural and female applicants were much more likely to receive negative responses from recruiters than male and urban applicants. We believe that our study is the first resume audit study to focus on potential ethnic discrimination in China's contemporary labor markets.

\section{Experiment design}

This experiment focuses on one very dynamic segment of China's labor market-the Internet job board sector. We employ the largest of the Chinese job boards, 51job.com, to investigate whether Chinese firms respond differently to job applications from ethnic minority and Han applicants. We denote ethnicity by using applicant names for ethnic minority job candidates that are recognizably different from those of the Han majority but typical of Mongolian, Uighur, and Tibetan individuals, respectively.

On a daily basis, millions of jobs are advertised on China's Internet job boards and many millions of applications are submitted in response. Some of these job boards are nationally recognized, while others focus on jobs in a particular region or city or on jobs of a particular type. Table 1 presents data on the number of page views for the three most popular job boards in China as of spring 2011.

Our experiment was large in scale-in the summer of 2011, we submitted 21,592 online applications for 10,796 advertised positions. We applied for positions in three different occupations: accountants, administrative assistants/specialists, and sales representatives. These occupations were chosen, in part, because they differ quite extensively in the degree to which their incumbents typically interact with firms' customers. The 
Table 1 Usage statistics for China's three largest internet job boards, Spring 2011

\begin{tabular}{lllll}
\hline 4/18/2011 & & $\begin{array}{c}\text { 51job.com } \\
\text { (前程无忧) }\end{array}$ & $\begin{array}{c}\text { chinahr.com } \\
\text { (中华英才) }\end{array}$ & $\begin{array}{c}\text { zhaopin.com } \\
\text { (智联招聘) }\end{array}$ \\
\hline Daily Page Views Estimate (PV) & Yesterday & $25,200,000$ & $3,760,000$ & $20,641,600$ \\
\cline { 2 - 5 } & Week's mean & $37,356,000$ & $5,350,400$ & $26,740,000$ \\
\cline { 2 - 5 } & Month's mean & $36,076,480$ & $5,396,352$ & $24,420,000$ \\
\cline { 2 - 5 } & Three-Month's mean & $34,268,256$ & $5,007,744$ & $23,070,536$ \\
\hline Mean Daily IP Visitor Volume Estimate*(IP) & Yesterday & $2,224,000$ & 616,000 & $1,520,000$ \\
\cline { 2 - 5 } & Week's mean & $2,248,000$ & 624,000 & $1,528,000$ \\
\cline { 2 - 5 } & Month's mean & $2,256,000$ & 614,400 & $1,504,000$ \\
\cline { 2 - 5 } & Three-Month's mean & $2,293,600$ & 604,800 & $1,519,200$ \\
\hline Mean Page Count Viewed per Visitor & & 15 & 9 & 19 \\
\hline Source: cn.alexa.com. The Alexa website provides detailed information on, and rankings of, page views for a variety of
\end{tabular}
Chinese websites.

diversity of occupations allows us to explore whether firms might discriminate in response to perceived customer preferences. They were also chosen for a very practical reason-there were thousands of job postings for each of these occupations.

We submitted applications in response to job ads posted for six cities that vary in terms of the size of their populations, geographic locations, prosperity, and ethnic composition. Nanjing (population 6.9 million), is a historically prominent and prosperous eastern seaboard city located in the lower reaches of the Yangtze River. It is the commercial, industrial, and political/administrative capital of Jiangsu Province. Shenzhen (population 10.4 million) is similarly located in a prosperous coastal region, but in the southern province of Guangdong on the Pearl River Delta. Shenzhen, a quiet backwater prior to its 1979 development as a special economic zone, has experienced extremely rapid growth and the in-migration of many millions of residents from many parts China. Chengdu and Kunming were chosen for this study due to their location in less prosperous western provinces. Chengdu (population 7.1 million), located in the heart of an agricultural, densely populated, interior province, Sichuan, is considered a local center of commerce and finance and transportation and communication and is an important part of China's 2000 Western Development Plan. Kunming (population 3.2 million), capital of southwestern China's Yunnan Province, was chosen because of its moderate size and because Yunnan is home to 25 of China's 55 officially recognized ethnic minorities. It is much more likely that employers and human resource professionals in Kunming have exposure to individuals of non-Han ethnicity than employers and human resource professionals in, say, Nanjing. Urumqi (population 2.3 million) and Hohhot (population 2.0 million) were included in this project because they are located in regions designated as autonomous minority areas. Urumqi, the capital of the Xinjiang Uighur Autonomous Region in northwest China, is an industrial and commercial center. Similarly, Hohhot is the capital of the Inner Mongolian Autonomous Region. It is not only an administrative center but also a cultural and commercial center. Even though both Urumqi and Hohhot are capitals of ethnic minority areas, the dominant ethnic group, in terms of population share, in each of these areas is Han.

To focus on ethnicity, we limited the range and scope of the resumes we created. Each of our resumes represented a 24-year old, single, currently employed, university-educated woman. Each resume was designed to be realistic in terms of job experience, education, 
certificates and training, and other personal information. The content of our fictitious resumes was based on observation of a very large number of resumes for the same types of occupations at the same levels of experience that were posted on a competing Internet job board, chinahr.com. The descriptions of tasks carried out by an applicant on her first and/or second job after college graduation were taken from these real resumes and appropriately edited and reassigned to our fictional resumes. The company names associated with our applicants' work history were altered to represent real companies operating in each of our target cities. After the resumes were built, they were randomly assigned a Han, Mongolian, Uighur, or Tibetan name ${ }^{8}$. Each resume was assigned an email address, mobile phone number, ID number, and regular home address.

Four versions of each person's resume were created that varied along two dimensions. In two of the four, the candidate had only one job/one employer since college graduation, and in the other two versions the candidate had already worked for two different companies. The variation in work history allows us to examine whether employers prefer candidates whose resumes seem to demonstrate stability (just one previous job) to those who might seem more ambitious/driven (those with two previous jobs and a history of increasing job responsibilities). For each of these two types of work history (one or two jobs), we created two types of educational experience-one in which the candidate was educated at a local university and one in which the candidate was educated at a similarly ranked university in another province. We wanted to eliminate, or at least mitigate, potential employer concern about language issues and/or minority language education, and thus ensured that each of our job candidate's university education took place either in the same city where the job was posted ${ }^{9}$ or in a province not known as, nor thought of, an ethnic minority area/minority autonomous region. We paid close attention to university rankings to ensure that each fictitious candidate within an occupational category had an education that would be viewed by employers to be of comparable quality. We attempted to create sets of resumes that were equivalent in terms of the applicants' productive characteristics. The registration process for the 51 job.com job board allowed us to upload the four different versions of each fictitious person's resume under one name with one email address and one mobile phone contact number.

Given China's hukou (residential registration) system, which limits where people may live and work, we worried that employers might be concerned about whether applicants with ethnic minority names had the right to live and work in the areas for which the jobs were posted. That is, we feared that a firm might pass over an application from a minority candidate based on presumptions about her hukou status if the resume failed to indicate that the applicant was very likely to be a local resident or had in some way already overcome any potential hukou limitations. To mitigate this concern, we designed our applicants' resumes such that each of the applicants already had several years of work history in the same city as that of the company's job posting. In half of our cases, the applicants had, additionally, attended a local university.

\section{Application process}

For a two-month period from mid-June to mid-August, we submitted a pair of applications for each suitable job posting in each of our three occupations in each of our six locations. By "suitable," we simply mean that our candidates' characteristics were a 
good match for the advertised position, that is, they appeared well qualified for the positions. For the cities of Chengdu, Kunming, Nanjing, and Shenzhen, we submitted one Han and one randomly chosen minority for each advertised position. Once the ethnic composition of the pair of applications was determined, we randomly chose one of the four versions of a candidates resume for submission for each applicant. The two resumes were submitted on the same day, usually within an hour or so of each other. For the city of Urumqi, we submitted one Han and one Uighur application and similarly for the city of Hohhot, we submitted one Han and one Mongolian application. The order of submission was randomly determined and tracked. Resume versions were also carefully tracked. As mentioned above, we submitted close to 22,000 applications over the course of the summer. However, Internet job boards were not as widely used in Urumqi and Hohhot as in our other cities--few jobs ads fitting our candidates' criteria were posted in these locations. We were therefore limited to submitting approximately 800 applications for the roughly 400 job postings in the two ethnic minority autonomous regions of our study.

We also collected as much information about the firm advertising each position as seemed feasible, given the scale of our experiment. We recorded each firm's name and, if available, the size of the firm (measured in terms of the number of its employees), and the type of firm ownership. The vast majority of firms that pursued/contacted our candidates did so by calling the mobile phones associated with each of our fictitious candidates. A very small number responded by email and an even smaller number responded by means of sending a text message to one of the mobile phones. We registered and recorded as a callback any action by a firm that indicated they were interested in the candidate and wanted to follow up with an interview or further contact of one sort or another. The student research assistants answering the calls were trained to immediately inform callers that the candidate had just accepted another position and was no longer interested in that firm's job opening. They responded in like manner to emails and followed up appropriately, usually with a phone call, to text messages.

\section{Analysis of results from the perspective of individual applicants}

There are large and statistically significant differences in the rates of interview callbacks received by applicants with Han-, Mongolian-, Uighur-, and Tibetan-sounding names. ${ }^{10}$ 1,389 of our 21,592 candidates received callbacks, yielding a callback rate of $6.43 \%$. That is, on average our candidates were contacted to set up interviews (or to carry out the next step(s) in the hiring process) by six or seven firms for each hundred applications that they submitted. The callback rates varied by candidate ethnicity from a high of $8.15 \%$ for those with typical Han names to a low of 3.69\% for those with typical Tibetan names.

The bottom row of Table 2 expresses the callback rates of those with Han-sounding names as a ratio relative to those with minority-sounding names. What these ratios reveal is that an equally qualified woman with a Mongolian-sounding name would need to put in $36 \%$ more applications than a woman with a Han-sounding name to get the same number of callbacks. Women with Uighur- and Tibetan-sounding names would need to put in $83 \%$ and $121 \%$ more applications, respectively, than women with Hansounding names in order to get the same number of callbacks for interviews. There appears to be a significant degree of discrimination (on the part of firms that participate in the Internet job board labor market) against women with ethnic minority names 
Table 2 Summary of applicant interview callback rates by ethnicity

\begin{tabular}{lccccr}
\hline Ethnicity & Han & Mongolian & Uighur & Tibetan & Total \\
\hline No. of Applications & 10,796 & 3,594 & 3,548 & 3,654 & 21,592 \\
\hline No. of Call Backs & 880 & 216 & 158 & 135 & 1389 \\
\hline Call Back Rate (\%) & 8.15 & 6.01 & 4.45 & 3.69 & 6.43 \\
\hline Call Back Ratio (Han/Minority) & 1.36 & 1.83 & 2.21 &
\end{tabular}

Note: The differences between the callback rates received by Han and Minority candidates are significant at the $1 \%$ level in each case.

(names that are clearly non-Han), relative to those with Han names. Of course, the resume audit methodology can only detect discrimination in one stage of the hiring process, but this early stage is the critical one of reviewing resumes in order to choose candidates for interviews.

The data in Table 3, indicate how the callback rates vary by ethnicity (as indicated by ethnically-differentiated names) across occupations. As discussed above, we expect that occupation may come into play as an explanatory variable in a couple of different ways. First, firms may treat candidates with ethnically-differentiated names differently if they believe their own customers have discriminatory preferences. If profit-maximizing firms try to accommodate their customers' (discriminatory) tastes, we'd expect that minority candidates in occupations that have more exposure/more interactions with the firms' customers are more discriminated against than those in occupations with low degrees of direct interaction with firms' customers. We expect that sales representatives are likely to interact more with firms' customers than administrative assistant/specialists and, in turn, that administrative assistant/specialists are likely to interact more with a firms' customers than accountants. Thus, we might expect the callbacks ratios for those applying for positions as sales representatives to vary more by ethnicity than those applying for accounting positions.

Second, it might be the case that the degree of slack or tightness in labor markets varies by occupation and that this will also affect the differences in callback rates (as oposed to callback ratios) by ethnicity across occupations. In tight labor markets firms could not as easily indulge either their own or their customers' discriminatory preferences (Bursell 2007). We can get a feel for the tightness of the labor markets by the overall callback rates by occupation.

Table 3 reveals several interesting patterns. (We first note that the number of applications per occupation was quite similar. The number of applications varied from a low of 7,030 for accounting positions to a high of 7,506 for sales representatives.) Here as in Table 2,

Table 3 Applicant interview callback rates (\%) and ratios by occupation and ethnicity

\begin{tabular}{lccccc}
\hline Ethnicity & Han & Mongolian & Uighur & Tibetan & Total \\
\hline Accounting: & 5.86 & 3.36 & 2.92 & 2.77 & 4.44 \\
$\quad$ Call back Ratio (Han/Minority) & & 1.74 & 2.01 & 2.12 & \\
Admin. Assistants: & 9.81 & 9.68 & 6.82 & 4.29 & 8.35 \\
$\quad$ Call back Ratio (Han/Minority) & & 1.01 & 1.44 & 2.29 & \\
Sales Representatives: & 8.74 & 5.14 & 3.64 & 4.03 & 6.50 \\
\multicolumn{2}{l}{ Call back Ratio (Han/Minority) } & 1.70 & 2.40 & 2.17 & \\
\hline
\end{tabular}

Note: The differences between the callback rates received by Han and Minority candidates are significant at the $1 \%$ level in each case for each occupation with one exception-- that between Han and Mongolian applicants for administrative assistant/specialists positions. 
there is a noticeable difference in callback rates by ethnicity. We observe a persistant pattern: women with Han-sounding names receive a higher rate of callbacks for interviews than do those with Mongolian-sounding names. Those with Mongolian-sounding names receive a higher rate of callbacks than those with Uighur-sounding names. And, those with Uigur-sounding names receive a higher rate of callback rates than those with Tibetan names. This pattern holds across each of our three occupations.

When we compare the ratio of Han/Minority callbacks for just accounting and sales representative positions, the two types of positions with the greatest difference in the degree of direct customer interaction, we observe very little difference in the ratios: the Han/Mongolian callback ratio for accounting is 1.74 while that for sales representatives is 1.70. Similarly, the Han/Uighur callback ratios for accounting and sales representatives are 2.01 and 2.40, respectively. The Han/Tibetan ratios for these two types of positions are 2.12 and 2.17 , respectively.

When we rank these occupations by the "tightness" of the labor market as evidenced by the overall callback rate, it appears that the market is tightest for administrative assistant/specialists. The overall callback rate for this occupation is $8.35 \%$. The overall callback rates for sales representatives and accountants are $6.50 \%$ and $4.44 \%$, respectively. It is in this relatively tight market for administrative assistant/specialists that we observe significantly lower callback ratios for Han/Mongolian and Han/Uighur ratios, that is, in this relatively tight market, Uighur and Mongolian candidates are treated in a fashion that is more akin to how Han are treated than was the case in the markets with more slack. This lends some support to the notion that the discrimination is taste based. It is more difficult for employers to indulge a taste for discrimination in a tight labor market.

As noted above, the cities chosen for this project vary considerably in terms of their geographic location, prosperity, and ethnic composition. Urumqi and Hohhot are polit$\mathrm{ical} /$ administrative capitals of minority automous regions that have provincial-level status. According to the 2000 Population Census of China, while the Xinjiang Uighur Automous Regions's officially designated ethnic minority populations constitute 59\% of its population, the population of its capital, Urumqi, is $75 \%$ Han. Similarly, the population of the Inner Mongolian Autonomous Region is predominantly Han, that is only $21 \%$ of its population is classified as minority, and the population of its capital, Hohhot, is only $13 \%$ minority. It seems that both differences in the ethnic composition of the cities in our study plus differences in local cultural norms could lead to differences in the treatment of ethnic minorities in the labor market by location. Callback rates and ratios by city are presented in Table 4, below.

In Chengdu, Kunming, Nanjing, and Shenzhen, our application procedure dictated that for each opening we submit pairs of applicants that consisted of one Han applicant and one randomly chosen applicant from those with Mongolian, Uighur, and Tibetan names. In Hohhot and Urumqi, we paired a Han applicant with an applicant of the dominant minority of each region. That is, in Urumqi we paired Han and Uighur applicants and in Hohhot we paired Han and Mongolian applicants.

Reading across the rows of Table 4 reveals that in both Chengdu and Shenzhen, each of our minorities (Mongolian, Uighur, and Tibetan) experienced callback rates that were significantly lower than those experienced by candidates with Han-sounding names. In Kunming, the callback rate for those with Mongolian-sounding names was 
Table 4 Applicant interview callback rates (\%) by city and ethnicity

\begin{tabular}{|c|c|c|c|c|c|}
\hline City & Han & Mongolian & Uighur & Tibetan & All Applicants \\
\hline Chengdu: Callback \% & 9.66 & $5.14^{*}$ & $3.98^{*}$ & $3.24^{*}$ & 6.84 \\
\hline Ratio (Han/Minority) & & 1.88 & 2.45 & 3.01 & \\
\hline No. of Apps for Chengdu & 3,105 & 914 & 955 & 1,236 & 6,210 \\
\hline Kunming: Callback \% & 9.40 & 11.08 & $6.72^{*}$ & 4.35 & 8.29 \\
\hline Ratio (Han/Minority) & & 0.84 & 1.38 & 2.18 & \\
\hline No. of Apps for Kunming & 2,148 & 659 & 685 & 804 & 4,296 \\
\hline Nanjing: Callback \% & 6.47 & 5.88 & 5.10 & $4.23^{*}$ & 5.78 \\
\hline Ratio (Han/Minority) & & 1.10 & 1.27 & 1.53 & \\
\hline No. of Apps for Nanjing & 2,119 & 748 & 686 & 685 & 4,238 \\
\hline Shenzhen: Callback \% & 7.19 & $3.17^{*}$ & $3.05^{*}$ & $3.34^{*}$ & 5.18 \\
\hline Ratio (Han/Minority) & & 2.27 & 2.36 & 2.15 & \\
\hline No. of Apps for Shenzhen & 3,019 & 1,074 & 1,016 & 929 & 6,038 \\
\hline Hohhot: Callback \% & 9.55 & 9.05 & N/A & N/A & 9.30 \\
\hline Ratio (Han/Mongolian) & & 1.06 & & & \\
\hline No. of Apps for Hohhot & 199 & 199 & & & 398 \\
\hline Urumqi: Callback \% & 2.43 & N/A & 3.88 & N/A & 3.16 \\
\hline Ratio (Han/Uighur) & & & 0.63 & & \\
\hline No. of Apps for Urumqi & 206 & & 206 & & 412 \\
\hline
\end{tabular}

Notes: * Indicates difference in callback rates between $\mathrm{Han}$ and minority is significant at the $5 \%$ level.

not significantly different from those with Han-sounding names. In Nanjing only the Tibetans had callback rates significantly lower that those with Han names.

Reading down the columns of Table 4 reveals that the only minority that experienced significantly lower rates of callbacks than Han in each of the four main cities were the Tibetans. The Uighurs had lower callback rates in three of the main cities, that is, in all locations except Kunming. The Mongolians experienced callback rates that were similar to that of the Han in Kunming and Nanjing and significantly lower callback rates in Chengdu and Shenzhen.

Turning now to the two cities in minority areas, in Hohhot, candidates with Mongolian names seemed to receive callbacks at rates very similar to those with Han names. This could be simply that minorities face much less discrimination or even receive favorable treatment in regions designated as autonomous minority regions. However, it was also the case that the overall callback rate in Hohhot was higher than elsewhere at 9.30\%. Thus the apparent lack of discrimination could also be the result of the tighter labor market which makes it more difficult for firms to discriminate. Comparing Hohhot to Urumqi gives some evidence that the results in Hohhot are not just the result of a tight labor market. In Urumqi, the overall callback rate was extremely low at $3.16 \%$. There, we observed that the callback rate for those with Uighur names was actually higher than that of those with Han names, but not statistically significantly so. (Given the small number of applications for Urumqi, it is not surprising that the difference between Uighur and Han callback rates was statistically insignificant.) The candidates with ethnic minority names in these two locations seemed to do as well as those with Han names. Employers and human resource managers may themselves be ethnic minorities ${ }^{11}$ or have much more experience with ethnic minorities and be less inclined to hold negative, implicit and explicit sterotypical attitudes of ethnic minority candidates. 


\section{Multivariate probit analysis - individual experience}

In Tables 2, 3, 4 above, we have sequentially discussed some of the factors that influence the callback rates received by candidates who are distinguished from each other only by whether their names sound as if they belong to one of China's more prominent ethnic minority groups (Mongolian, Uighur, or Tibetan) or to the Han majority. In this section of the paper, we explore how these factors interact. We estimate a probit regression with the dependent variable indicating whether or not a candidate received a callback for an interview. The independent variables include controls for a candidate's ethnicity, occupation, and location ${ }^{12}$. We also created control variables to track resume characteristics such as whether the candidate had one or two previous jobs in the years since graduating from university and whether the candidate obtained her university education in the same city as the job posting or in another province.

The results in Table 5 show that even after controlling for all other factors, there is a statically significant difference in the callback rates for candidates with each type of ethnic minority name relative to the base case of candidates with Han-sounding names. Given the callback rates of $6.43 \%$ overall and $8.15 \%$ for Han candidates, the size of these marginal effects are very large. The candidates with Mongolian names

Table 5 Marginal effects of the determinants of interview callbacks received by young women with ethnically-differentiated names in response to applications submitted through Chinese internet job boards

\begin{tabular}{|c|c|c|c|c|}
\hline \multicolumn{5}{|l|}{ Probit Statistics: } \\
\hline \multicolumn{3}{|l|}{ Number of Observations } & \multicolumn{2}{|l|}{21,592} \\
\hline \multicolumn{3}{|l|}{ Wald chi2() } & \multicolumn{2}{|l|}{404.24} \\
\hline \multicolumn{3}{|l|}{ Prob > chi2 } & \multicolumn{2}{|l|}{0.0000} \\
\hline \multicolumn{3}{|l|}{ Log pseudolikelihood } & \multicolumn{2}{|l|}{$-5,000.56$} \\
\hline \multicolumn{3}{|l|}{ Actual rate of callbacks } & \multicolumn{2}{|l|}{0.064} \\
\hline \multicolumn{5}{|c|}{ Average Marginal Effects on Prediction of Callback } \\
\hline Marginal Effects & $\mathrm{dy} / \mathrm{dx}$ & Std.Err. & z & $\mathbf{P}>\mathbf{z}$ \\
\hline \multicolumn{5}{|c|}{ Indicator of Ethnicity of Name } \\
\hline Mongolian & -0.022 & 0.004 & -5.91 & 0.000 \\
\hline Uighur & -0.035 & 0.004 & -10.04 & 0.000 \\
\hline Tibetan & -0.045 & 0.003 & -13.77 & 0.000 \\
\hline \multicolumn{5}{|l|}{ base: Han } \\
\hline \multicolumn{5}{|c|}{ Indicator of Advertised Occupation } \\
\hline Accounting & -0.021 & 0.005 & -4.39 & 0.000 \\
\hline Admin. Assistant & 0.017 & 0.006 & 312 & 0.002 \\
\hline \multicolumn{5}{|l|}{ (base: Sales Rep.) } \\
\hline \multicolumn{5}{|l|}{ Indicator of Job Location } \\
\hline Chengdu & 0.009 & 0.006 & 1.51 & 0.131 \\
\hline Kunming & 0.023 & 0.007 & 3.26 & 0.001 \\
\hline Urumqi & -0.025 & 0.012 & -2.08 & 0.037 \\
\hline Shenzhen & -0.007 & 0.006 & -1.09 & 0.277 \\
\hline Hohhot & 0.030 & 0.020 & 1.51 & 0.130 \\
\hline \multicolumn{5}{|l|}{ (base: Nanjing) } \\
\hline \multicolumn{5}{|c|}{ Indicators for Education Received in/out of Province and Job Stabilty } \\
\hline Locally Educated & 0.010 & 0.003 & 2.98 & 0.003 \\
\hline Only One Previous Job & 0.008 & 0.003 & 2.54 & 0.011 \\
\hline
\end{tabular}

Notes: Name ethnicity and occupation are fully interacted in underlying probit. 
have a callback rate that is 2.2 percentage points lower than that of the Han, while the Uighur and Tibetan rates are 3.5 and 4.5 percentage points lower, respectively, than that of the Han.

Table 6 reports the results of the Chi-squared tests, based on the probit regression underlying Table 5, which allow us to compare the callback rates of each ethnic group to one another. It reveals that the callback rates for the minorities are not just significantly different from those received by candidates with Han names. The callback rates of the candidates with Mongolian names are significantly higher than those received by those with Uighur and the Tibetan names. And, the callback rate received by those Uighur names are significantly higher than that received by those with Tibetan names.

The marginal effects presented in Table 5 also reveal that firms have clear preferences on resume characteristics. All else equal, the callback rate for candidates with just one previous job was 1 percentage point higher than for those with two previous jobs. (Recall that all of our candidates are 24 years old and had graduated from university approximately 2 to 3 years before applying for the posted positions.) Similarly, firms seem to value local education. All else equal, those who attended university in the same city as the job posting received callbacks rates almost 1 percentage point higher than those educated at universities in other provinces. Although these results are interesting in and of themselves, they also provide evidence that the reviewers are carefully reading resumes and not making random calls. This evidence (that resume screeners are carefully reading resumes) adds more weight to the findings of discrimination on ethnic sounding names.

There are also significant differences by both occupation and location, suggesting that the labor market conditions differ substantially across these dimensions. In the summer of 2011, the callback rate for accounting positions was over 2 percentage points lower than that of sales representative while that for administrative assistant/ specialists was almost 2 percentage points higher. The labor market conditions in Kunming seemed to facilitate the chances of getting interview callbacks. The callback rate in Urumqi was quite low; perhaps, given the paucity of job postings there, Internet job boards were not yet in common use and/or when used, not fully trusted as a good source of job candidates. Of course, the low callback rate may also simply reflect local labor market conditions.

In a separate probit regression (not reported here) we also explore the effects of location further by interacting controls for the cities in autonomous minority areas (Urumqi and Hohhot) with controls for their own minorities (Uighurs in Urumqi and Mongolian in Hohhot). Even with the relatively low number of job postings in these areas, we obtain significant results. The interaction term of Hohhot and Mongolian completely and exactly offsets the negative effect of Mongolian ethnicity relative to the Han, that is, the Mongolians in Hohhot suffer no disadvantage due to their ethnicity in getting interview callbacks. However, it is important to note that neither are they

Table 6 Chi-squared tests of differences in callback rates between minorities

\begin{tabular}{lccc}
\hline & \multicolumn{2}{c}{ Tests for Equality in the Marginal Effects by Ethnicity in Obtaining a Callback } \\
\hline & \multicolumn{1}{c}{ Mongolian=Uighur } & Mongolian=Tibetan & Uighur=Tibetan \\
\hline chi2(1) & 6.54 & 21.29 & 4.13 \\
Prob $>$ chi2 & 0.0105 & 0.0000 & 0.0421 \\
\hline
\end{tabular}


advantaged in their own minority region. The situation of the Uighurs in Urumqi is different. There is a positive and large coefficient on the interaction term of Urumqi and Uighur, which suggests that Uighurs are advantaged in getting callbacks in their own minority area. All else equal, in Urumqi, candidates with Uighur names are more likely to receive callbacks than candidates with Han names.

Our findings thus far indicate that ethnic minority job candidates are the recipients of discriminatory treatment. Their callback rates are significantly lower than those received by equally qualified candidates with Han names. This, however, does not imply that all firms discriminate. We turn now to an analysis of our firm data.

\section{Results-analysis of firms making callbacks}

Our job candidates received a total of 1,389 interview callbacks. 944 different firms made these callbacks. Some of our firms contacted only candidates with Han names, some contacted only candidates with minority names, and some contacted both. In this section of the paper, we examine the characteristics of firms that appear to treat candidates of differing ethnicity equally and those that seem to favor those of one ethnicity over another. We have organized our results according to two sets of firm characteristics: firm ownership (Tables 7 and 8) and firm size (Tables 9 and 10) and by the ethnicities of the pair of candidates submitted to each firm (Tables 11 and 12). In each of these sets of tables, the first table contains the results for all 944 firms making at least one callback. The second tables repeat the analysis for firms located only in Urumqi and Hohhot, the two autonomous minority areas.

The first row of Table 7 reveals that the share of firms making callbacks to both of the candidates (47\%) is effectively equal to the share calling only Han candidates (46\%). Only $7 \%$ of firms made callbacks to minorities only. The remaining rows of the table indicate that firms of one type of ownership clearly stand out from the rest: the firms under state ownership are much less likely than firms under other forms of ownership to call only Han candidates and much more likely to call back both candidates, that is, state-owned firms have the highest propensity to treat minority and Han candidates equally.

Table 7 Firm callback patterns by firm ownership and candidate ethnicity

\begin{tabular}{|c|c|c|c|c|c|}
\hline \multicolumn{6}{|c|}{ Number and Frequency of Firms Making Callbacks to: } \\
\hline Firm Ownership & & Han Candidate Only & Minority Candidate Only & Both Candidates & Total \\
\hline \multirow[t]{2}{*}{ All Firms } & No. & 435 & 64 & 445 & 944 \\
\hline & $\%$ & 46.08 & 6.78 & 47.14 & 100 \\
\hline \multirow[t]{2}{*}{ Private } & No. & 315 & 50 & 315 & 680 \\
\hline & $\%$ & 46.32 & 7.35 & 46.32 & 100 \\
\hline \multirow[t]{2}{*}{ Joint Venture } & No. & 32 & 3 & 31 & 66 \\
\hline & $\%$ & 48.48 & 4.55 & 46.97 & 100 \\
\hline \multirow[t]{2}{*}{ Foreign } & No. & 56 & 2 & 56 & 114 \\
\hline & $\%$ & 49.12 & 1.75 & 49.12 & 100 \\
\hline \multirow[t]{2}{*}{ State } & No. & 14 & 3 & 27 & 44 \\
\hline & $\%$ & 31.82 & 6.82 & 61.36 & 100 \\
\hline \multirow[t]{2}{*}{ Unknown } & No. & 18 & 6 & 16 & 40 \\
\hline & $\%$ & 45 & 15 & 40 & 100 \\
\hline
\end{tabular}


Table 8 Firm callback patterns in minority autonomous regions by firm ownership and candidate ethnicity

\begin{tabular}{|c|c|c|c|c|c|}
\hline \multicolumn{6}{|c|}{ Number and Frequency of Firms Making Callbacks to: } \\
\hline Firm Ownership & & Han Candidate Only & Minority Candidate Only & Both Candidates & Total \\
\hline \multirow[t]{2}{*}{ Total } & No. & 5 & 7 & 19 & 31 \\
\hline & $\%$ & 16.13 & 22.58 & 61.29 & 100 \\
\hline \multirow[t]{2}{*}{ Private } & No. & 2 & 5 & 9 & 16 \\
\hline & $\%$ & 12.5 & 31.25 & 56.25 & 100 \\
\hline \multirow[t]{2}{*}{ Joint Venture } & No. & 2 & 0 & 3 & 5 \\
\hline & $\%$ & 40 & 0 & 60 & 100 \\
\hline \multirow[t]{2}{*}{ Foreign } & No. & 1 & 1 & 3 & 5 \\
\hline & $\%$ & 20 & 20 & 60 & 100 \\
\hline \multirow[t]{2}{*}{ State } & No. & 0 & 0 & 1 & 1 \\
\hline & $\%$ & 0 & 0 & 100 & 100 \\
\hline \multirow[t]{2}{*}{ Unknown } & No. & 0 & 1 & 3 & 4 \\
\hline & $\%$ & 0 & 25 & 75 & 100 \\
\hline
\end{tabular}

In Table 8, we see that firms located in minority areas are much more likely to callback both candidates than is the case for the whole sample of firms $(61 \%$ vs. $47 \%$ in Table 7). We also observe a higher share of firms making callbacks to minority only candidates $(23 \%$ vs. $7 \%$ ) and a lower share of firms making callbacks to Han only candidates (16\% vs. $46 \%)$. Firms in minority areas are most likely to callback both candidates, but when they make only one call, it is more likely to be to a candidate with a minority name than a candidate with a Han name (23\% vs. $16 \%)$. Unfortunately, the sample of firms making callbacks in minority areas is too small to make any definitive statements on differentiation by ownership type

In the next pair of tables, we explore the hypothesis that firm size may be related to firms' decisions about whom to call back. Employers may choose to hire candidates of one ethnicity over another because they prefer to have employees that are culturally similar to them. That is, firms may be making choices that are based simply on employer tastes or preferences that are not related to firm productivity (Bursell 2007). If so, it is possible that we would observe less discrimination in large companies than small ones as it may be the case that social

Table 9 Firm callback patterns by firm size (number of employees) and candidate ethnicity

\begin{tabular}{lccccc}
\hline \multicolumn{7}{c}{ Number and Frequency of Firms Making Callbacks to: } \\
\hline Firm Size & & Han Candidate Only & Minority Candidate Only & Both Candidates & Total \\
\hline Medium $50-500$ & No. & 206 & 24 & 231 & 461 \\
\hline & $\%$ & 44.69 & 5.21 & 50.11 & 100 \\
\hline Small $<50$ & No. & 107 & 25 & 99 & 231 \\
\hline & $\%$ & 46.32 & 10.82 & 42.86 & 100 \\
\hline Large $>500$ & No. & 118 & 11 & 111 & 240 \\
\hline & $\%$ & 49.17 & 4.58 & 46.25 & 100 \\
\hline Unknown & No. & 4 & 4 & 4 & 12 \\
\hline & $\%$ & 33.33 & 33.33 & 33.33 & 100 \\
\hline Total & No. & 435 & 64 & 445 & 944 \\
\hline & $\%$ & 46.08 & 6.78 & 47.14 & 100 \\
\hline
\end{tabular}


Table 10 Firm callback patterns in minority autonomous regions (Hohhot and Urumqi) by firm size (number of employees) and candidate ethnicity

\begin{tabular}{lccccc}
\hline \multicolumn{7}{c}{ Number and Frequency of Firms Making Callbacks to: } \\
\hline Firm Size & & Han Candidate Only & Minority Candidate Only & Both Candidates & Total \\
\hline Medium $50-500$ & No. & 2 & 2 & 7 & 11 \\
\hline & $\%$ & 18.18 & 18.18 & 63.64 & 100 \\
\hline Small $<50$ & No. & 0 & 1 & 1 & 2 \\
\hline & $\%$ & 0 & 50 & 50 & 100 \\
\hline Large $>500$ & No. & 3 & 4 & 9 & 16 \\
\hline & $\%$ & 18.75 & 25 & 56.25 & 100 \\
\hline Unknown & No. & 0 & 0 & 2 & 2 \\
\hline & $\%$ & 0 & 0 & 100 & 100 \\
\hline Total & No. & 5 & 7 & 19 & 31 \\
\hline & $\%$ & 16.13 & 22.13 & 61.29 & 100 \\
\hline
\end{tabular}

interactions between owners/managers and their employees are less important in large companies than small ones.

In Table 9, a mixed picture emerges. While the share of small (those with 50 or fewer employees) firms' callbacks going to minority only candidates $(10.8 \%)$ is significantly higher than the shares of callbacks to minority only candidates at medium (5.2\%) and large firms (4.6\%), the share of small firms' callbacks to both candidates $(42.9 \%)$ is significantly lower than the share of callbacks to both candidates at medium-sized firms (50.1\%). Although small companies seem slightly less likely than large companies to discriminate against ethnic minority candidates in the sense of having higher callback shares for Han only candidates ( $47 \%$ vs. $49 \%)$ and slightly more likely to callback Han only candidates than medium-sized companies ( $47 \%$ vs. $45 \%)$, these differences are not statistically significant.

When we separate out the callbacks made by firms in minority autonomous regions, we see that the share of callbacks to both candidates by firms of all sizes is $50 \%$ or greater. (See Table 10.) We also observe that shares of callback by firms in minority areas to minority only candidates is as least as high as the share of callbacks going to Han only candidates. Firms in minority areas appear to treat minority candidates equitably.

In Table 11, we see that the ethnic composition of candidate pairs matters. Mongolian-Han candidate pairs have a lower share of Han only callbacks than do

Table 11 Firm callback patterns by ethnic composition of candidate pairs

\begin{tabular}{|c|c|c|c|c|c|}
\hline \multicolumn{6}{|c|}{ Number and Frequency of Firms Making Callbacks to: } \\
\hline Firm Size & & Han Candidate Only & Minority Candidate Only & Both Candidates & Total \\
\hline \multirow[t]{2}{*}{ Mongolian-Han Pair } & No. & 134 & 38 & 178 & 350 \\
\hline & $\%$ & 38.29 & 10.86 & 50.86 & 100 \\
\hline \multirow[t]{2}{*}{ Uighur-Han Pair } & No. & 144 & 18 & 140 & 302 \\
\hline & $\%$ & 47.68 & 5.96 & 46.36 & 100 \\
\hline \multirow[t]{2}{*}{ Tibetan-Han Pair } & No. & 157 & 8 & 127 & 292 \\
\hline & $\%$ & 53.77 & 2.74 & 43.49 & 100 \\
\hline \multirow[t]{2}{*}{ Total } & No. & 435 & 64 & 445 & 944 \\
\hline & $\%$ & 46.08 & 6.78 & 47.14 & 100 \\
\hline
\end{tabular}

Notes: The callback rate of firms to minority candidates only is significantly higher for Mongolian-Han pairs than others. The call backrate of firms to Han candidates only is significantly lower for Mongolian-Han pairs than others. 
Table 12 Firm callback patterns in minority autonomous regions (Hohhot and Urumqi) by ethnic composition of candidate pairs

\begin{tabular}{|c|c|c|c|c|c|}
\hline \multicolumn{6}{|c|}{ Number and Frequency of Firms Making Callbacks to: } \\
\hline Firm Size & & Han Candidate Only & Minority Candidate Only & Both Candidates & Total \\
\hline \multirow[t]{2}{*}{ Mongolian-Han Pair } & No. & 3 & 2 & 16. & 21 \\
\hline & $\%$ & 14.29 & 9.52 & 76.19 & 100 \\
\hline \multirow[t]{2}{*}{ Uighur-Han Pair } & No. & 2 & 5 & 3 & 10 \\
\hline & $\%$ & 20 & 50 & 30 & 100 \\
\hline \multirow[t]{2}{*}{ Total } & No. & 5 & 7 & 19 & 31 \\
\hline & $\%$ & 16.13 & 22.58 & 61.29 & 100 \\
\hline
\end{tabular}

Uighur-Han or Tibetan-Han pairs. In addition, Mongolian-Han pairs have higher shares of callbacks for minority only and both called than do Uighur-Han or TibetanHan pairs of applicants. In Table 12, we see that firms in Hohhot, which received only Mongolian-Han pairs, were highly likely to contact both their Han and Mongolian candidates for interviews. Firms in Urumqi, which received only Uighur-Han pairs, seemed quite inclined to contact only Uighur candidates for interviews. Of course, the number of firms in minority areas making callbacks is very small. Therefore, the results for the autonomous regions should be viewed as suggestive only.

\section{Multinomial probit -analysis of firms that make callbacks}

In the above analysis, we've examined tables of firm callback patterns by firm ownership, firm size, and the ethnic composition of candidate pairs. In each case there are some significant factors that help to explain differences in firm behavior with respect to choosing which candidates to call back for interviews. We now combine these factors in a multinomial probit regression. The dependent variable is a categorical variable that indicates whether firms call back only candidates with Han names, only candidates with minority names, or both types of candidates. The independent variables include indicators for the ethnic composition of the candidate pair submitted to each firm, the occupation of the advertised position, the location of the job posting, firm ownership type, and firm size. In addition, we have included a set of indicators that take on the value one when only the Han applicant had local education, when only the Han applicant had one previous job, when only the minority applicant had local education, and when only the minority applicant had one previous job $^{13}$. (These characteristics were revealed as preferred in the individual level analysis of the previous section.)

In the multinomial probit, we use equal treatment as the base outcome, that is, that firms callback both candidates for interviews. Table 13 consists of three panels that reveal the marginal effects of our control variables on the predicted outcomes: a) that firms make callbacks only to Han candidates; b) that firms make callbacks only to minority candidates; or c) that firms make callbacks to both candidates ${ }^{14}$.

What factors help to explain whether a firm will call back only the Han candidate from the pair of applications it received? Panel A of Table 13 reveals that all else equal, firms that receive Han-Tibetan pairs are 8.4 percentage points more likely to call only the Han candidate than firms that receive applications from Han-Mongolian pairs. In addition, it appears that human resource managers are paying attention to resume characteristics: all else equal, if the pair of resumes submitted to a firm was such that the 
Table 13 Marginal effects of the determinants of the callback patterns of firms in response to paired Han and minority applicants

\begin{tabular}{|c|c|c|c|c|c|c|}
\hline \multicolumn{7}{|l|}{ Multinomial Probit Statistics: } \\
\hline \multicolumn{3}{|l|}{ Number of Observations } & \multicolumn{4}{|l|}{944} \\
\hline \multicolumn{3}{|l|}{ Wald Chi2(40) } & \multicolumn{4}{|l|}{293.26} \\
\hline \multicolumn{3}{|l|}{ Prob chi2 } & \multicolumn{4}{|l|}{0.000} \\
\hline \multicolumn{3}{|l|}{ Log Likelihood } & \multicolumn{4}{|c|}{-740.243} \\
\hline Average Marginal Effects on Predicted Outcomes: & \multicolumn{2}{|c|}{$\begin{array}{l}\text { Panel A: Firms } \\
\text { Call Back Only } \\
\text { the Han }\end{array}$} & \multicolumn{2}{|c|}{$\begin{array}{c}\text { Panel B: Firms } \\
\text { Call Back Only } \\
\text { the Minority }\end{array}$} & \multicolumn{2}{|c|}{$\begin{array}{l}\text { Panel C: Firms } \\
\text { Call Back Both } \\
\text { Applicants }\end{array}$} \\
\hline Control Variables & $\mathrm{dy} / \mathrm{dx}$ & $\mathbf{z}$ & $\mathrm{dy} / \mathrm{dx}$ & 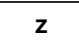 & $\mathrm{dy} / \mathrm{dx}$ & $\mathbf{z}$ \\
\hline \multicolumn{7}{|l|}{ Indicator of Ethnic Composition of Paired Applicants } \\
\hline Han-Tibetan pair of applicants & 0.084 & 2.38 & -0.100 & -4.83 & 0.016 & 0.044 \\
\hline Han-Uiguhr pair of applicants & 0.045 & 1.27 & -0.089 & -4.62 & 0.044 & 1.21 \\
\hline
\end{tabular}

Indicators of Potentially Preferable Resume Characteristics within an Applicant Pair

\begin{tabular}{|c|c|c|c|c|c|c|}
\hline Only Han applicant had single previous job & -0.013 & -0.36 & 0.003 & 0.17 & 0.010 & 0.26 \\
\hline Only Han applicant had local education & 0.118 & 3.31 & -0.010 & -0.52 & -0.108 & -2.93 \\
\hline Only minority applicant had single previous job & -0.089 & -2.43 & 0.027 & 1.45 & 0.062 & 1.67 \\
\hline Only minority applicant had local education & -0.109 & -2.99 & 0.002 & 0.10 & 0.107 & 2.90 \\
\hline \multicolumn{7}{|l|}{ Base cases:same job histories/ education location } \\
\hline \multicolumn{7}{|l|}{ Indicator of Advertised Occupation } \\
\hline Firm advertising accounting position & -0.020 & -0.49 & -0.092 & -3.68 & 0.111 & 2.72 \\
\hline Firm advertising administrative assistant position & -0.169 & -5.45 & -0.012 & -0.75 & 0.181 & 5.69 \\
\hline \multicolumn{7}{|l|}{ Base case: Firm advertising sales position } \\
\hline \multicolumn{7}{|l|}{ Indicator of Location of Job Posting } \\
\hline Chengdu & 0.212 & 5.65 & -0.153 & -5.48 & -0.059 & -1.47 \\
\hline Kunming & 0.014 & 0.31 & 0.005 & 0.26 & -0.019 & -0.43 \\
\hline Urumqi & -0.161 & -0.92 & 0.211 & 3.86 & -0.049 & -0.28 \\
\hline Shenzhen & 0.219 & 5.20 & -0.063 & -2.79 & -0.157 & -3.56 \\
\hline Hohhot & -0.218 & -1.72 & -0.072 & -1.45 & 0.290 & 2.39 \\
\hline \multicolumn{7}{|l|}{ Base case: Nanjing } \\
\hline \multicolumn{7}{|l|}{ Indicator of Firm Ownership Type } \\
\hline Firm under joint ownership & 0.008 & 0.13 & -0.058 & -1.59 & 0.050 & 0.78 \\
\hline Firm under foreign ownership & 0.011 & 0.21 & -0.115 & -2.77 & 0.104 & 2.00 \\
\hline Firm state-owned & -0.138 & -1.80 & -0.026 & -0.64 & 0.164 & 2.15 \\
\hline Type of firm ownership unknown & -0.061 & -0.71 & 0.036 & 0.92 & 0.025 & 0.28 \\
\hline \multicolumn{7}{|l|}{ Base case: firm privately owned } \\
\hline \multicolumn{7}{|l|}{ Indicator of Firm Size } \\
\hline Small firm < 50 employees & 0.013 & 0.35 & -0.001 & -0.06 & -0.012 & -0.31 \\
\hline Large firm > 500 employees & 0.045 & 1.17 & -0.007 & -0.30 & -0.038 & -0.97 \\
\hline Firm size unknown & 0.143 & 0.81 & 0.134 & 2.36 & -0.277 & -1.55 \\
\hline Base case: medium sized firm & & & & & & \\
\hline
\end{tabular}


Han candidate had local education when the minority candidate did not, the firm was more likely to callback only the Han. Similarly if the minority candidate had more desirable resume characteristics in terms of local education or job stability (only one previous job) when the Han had out of province education and/or two previous jobs, then the probability of the firm calling only the Han candidate was significantly lowered.

Location also matters. Firms posting jobs in Chengdu and Shenzhen are 21.2 and 21.9 percentage points more likely to choose only Han candidates for interviews than firms in Nanjing. The result is quite surprising given that Nanjing is a very traditional Chinese city with a very long history while Shenzhen is a recently developed city full of migrants. We might have expected that difference was more of a norm in Shenzhen. In contrast, firms in Hohhot are 21.8 percentage points less likely than firms in Nanjing to choose only Han candidates for interviews.

If firms are accommodating customer preferences for dealing with Han employees, we expect that firms might have higher rates of callbacks for Han only candidates in the occupations that have more direct customer interactions. Not surprisingly, firms advertising administrative assistants positions are 16.9 percentage points less likely to contact only Han candidates than firms advertising sales representative openings. The market for administrative assistant/specialists was the tightest of our three occupationallydifferentiated markets. Somewhat more surprising is the lack of significant difference in this respect between firms advertising accounting and sales representative openings. Accountants have much less direct customer contact that sales representatives.

Here, as in the bivariate analysis of Table 7, state-owned firms seem to distinguish themselves from all other forms of ownership. They are 13.8 percentage points less likely than privately-owned firms to call only candidates with Han names.

What factors help to explain whether a firm will call back only the minority candidate? Table 13 Panel B reveals that firms clearly prefer candidates with Mongolian names to those with Uighur or Tibetan names. If a firm is going to call back only a minority candidate, it is 10 and 8 percentage points more likely to do so when the pair contains a woman with a Mongolian name than a woman with a Uighur or Tibetan name. Firms that advertised accounting positions are 9.2 percentage points less likely to callback minority only candidates than those advertising openings for sales representatives. Firms in Chengdu and Shenzhen appear to behave significantly differently from firms in Nanjing; they are less likely to call minority only candidates. Firms in Urumqi are more likely to call only minority candidates.

State-owned firms are not significantly more likely to callback minority only candidates than privately-owned firms, that is, they do not appear to advantage minority candidates. Foreign-owned firms, however, are significantly less likely to callback only minority candidates.

Panel C of Table 13 reveals the marginal effects of our control variables on the outcome of equal treatment, that is, that firms call back both candidates. The marginal effects in this panel are the sums of the effects of the same variable in Panels A and Panel B. However, it seems convenient for purposes of discussion to present them in their own panel. Firms that call back both minority and Han candidates don't seem to care about the particular ethnic composition of the pair. There is an interesting opposition in the sign of the marginal effects on preferable resume characteristics. On the one hand, firms that received a pair of resumes in which the Han candidate had local 
education when the minority did not, were 10.8 percentage points less likely to call back both candidates. (Such firms were instead more likely to call only the Han candidate.) On the other hand, when a firm received a pair of applications in which the minority candidate had local education when the Han did not, it was more likely to call back both candidates. Thus, firms responded differently to deliberately controlled resume characteristics depending on whether the Han or the minority candidate had the more desirable characteristic. A better resume characteristic on a Han resume appeared to give the Han candidate a better chance of getting the firm's only callback. A better characteristic on a minority resume did not better the minority candidate's chances of getting a firm's only callback, but did improve the chances that the firm would contact both minority and Han candidates for interviews. This is a very subtle form of discrimination but leads to different callback rates experienced by the individuals. State-owned and foreign-owned firms were more likely than privately-owned firms, all else held constant, to offer interviews to both minority and Han candidates.

\section{Conclusions}

This study employs a resume audit design to explore how Chinese firms respond to job applications that vary only in terms of the ethnicity of the candidates' names. Our study focuses on a very dynamic and rapidly increasing segment of the China's labor markets-the Internet job boards. Labor law in China distinctly states the employees and job seekers must not be discriminated against on the basis of their ethnicity. We find however, clear evidence of discrimination. Female job seekers with Mongolian names would need to submit 36\% more applications than equally qualified women with Han names to get the same number of callbacks. The situation is even worse for women with Uighur and Tibetan names who must submit 83 and 121\% more applications, respectively, to get as many callbacks as women with Han names.

Minority candidates applying for jobs posted in one of the two autonomous minority regions included in this study do not experience this type of discrimination. There is no apparent difference in the treatment of Mongolian and Han applicants in Hohhot. And, Uighur applicants in Urumqi experience a positive advantage over Han candidates in their job searches.

In our analysis at the firm level, we find that not all firms discriminate. In our sample of firms that make callbacks in response to at least one of the two applications they receive, the majority (54\%) either call back both applicants, that is, they treat Han and minority applicants alike (47\%) or call back only their minority applicant (7\%). However, a disturbingly large percentage $(46 \%)$ of firms give preference to applicants with Han names, that is, they only call back Han applicants.

Some characteristics of firms do matter, state-owned firms are significantly less likely than firms under other forms of ownership to give preference to candidates with Han names in setting up interviews. Firms in different locations tend to behave differently. Those in Chengdu and Shenzhen are much more likely to choose only Han candidates than firms in Nanjing, while firms in Hohhot are much less likely than those in Nanjing to give preference to Han candidates. Firm size does not seem to play a role in determining the likelihood that a firm might discriminate against minorities.

Our analysis at both the individual and the firm levels clearly indicates that human resource managers screening resumes are paying attention to resume characteristics. 
For these positions, advertised to those with 1 to 3 years work experience, they clearly prefer candidates who have not previously changed jobs. They also prefer to hire locally educated candidates. That screeners are paying attention to resume characteristics suggests a rather simple solution to mitigate some of the discrimination against minority candidates participating in the Internet job board labor market. If job board companies institute a system wherein resumes are submitted to firms with identifying numbers rather than names, minority candidates would be much more likely to get the proverbial foot in the door at this critical stage of the hiring process-getting an interview. Unfortunately, if discrimination takes place based on the relatively abstract level of resume name differentiation, it is also likely to take place during in-person interviews ${ }^{15}$.

\section{Endnotes}

${ }^{1}$ This project was reviewed and approved by the co-chairs of the Institutional Review Board of Bates College.

${ }^{2}$ See for examples Bertrand and Mullainathan (2004), Booth, Leigh, and Varganova (2011), Bursell (2007), Kaas and Manger (2011), Oreopoulos and Dechief (2011), Riach and Rich (2002), and Siddique (2008).

${ }^{3}$ For example, in 2002, the minority population of the Inner Mongolian Autonomous Region constituted only 20.9 percent of its total population. Comparable figures for Guangxi Zhuang and the Ningxia Hui Autonomous Regions are 38.4 percent and 35.4 percent, respectively. Tibet and Xinjiang Uighur Autonomous Regions are notable exceptions, with the minority populations constituting 96.7 and 60.13 .

${ }^{4}$ See for example China's Yearbook of Ethnic Works (SEAC 2003), China's Ethnic Statistical Yearbook (SEAC and NBS 2000), and the Statistical Yearbooks of China (NBS 2005).

${ }^{5}$ Barabantseva (2009) notes that although the rhetoric surrounding the Western Development Plan suggests that it was designed specifically for ethnic minorities and minority areas, one of its core elements is the opening of the areas natural resources for the benefit of the rest of the country. core elements is the opening of the areas natural resources for the benefit of the rest of the country.

${ }^{6}$ The evidence on the existence and extent of underlying discrimination is mixed. Hasmath (2012b) presents evidence that Uighurs are underrepresented in high-paying, high-status jobs in Xinjiang's urban areas. Howell and Fan (2011) show that among recent self-initiated migrants to Urumqi, Xinjiang's capital, the Uighurs are faring better than the Han in terms of occupational status and remuneration.

${ }^{7}$ See for example, Riach and Rich (2002), Bertrand and Mullainathan (2004), and Pager (2007).

${ }^{8}$ Although in China, an individual's official ethnicity is recorded on his/her identity card, we did not explicitly state our candidate's official ethnicity on resumes since 1) there were no fill-in blanks or check boxes for this purpose on the up-loadable forms and 2) we did not find any examples of candidates stating their ethnicity in the sample of real resumes we examined.

${ }^{9}$ For job postings in the city of Shenzhen, we counted education obtained in the nearby city of Guangzhou as local.

${ }^{10}$ Hasmath (2011) argues that a fairly large share of urban jobs in China are obtained through personal network searches and that there is a higher propensity for ethnic 
minority disadvantages when jobs are obtained through such channels. If so, the results presented here may rather represent a lower bound for the degree of discrimination faced by job candidates of these ethnic groups.

${ }^{11}$ We were unable to tell from the job postings whether the firms to which we submitted applications were minority owned. We were also unable to determine anything about the ethnic status of the human resource professionals who screened the resumes.

${ }^{12}$ In the underlying probits, we fully interact ethnicity and occupation. It would be desirable to also fully interact these variables with location. However the application process that limited the ethnicity of applicants submitted in response to job ads for Hohhot and Urumqi in combination with the small number of job postings in these two cities left several cells either empty or with too few responses to be able to calculate marginal effects. We estimated a model with a full set of interactions of the ethnicity, occupation, and location variables for the subset of the data that excluded the 810 observations from Hohhot and Urumqi. We found the marginal effects to be virtually identical to those presented in Table 5.

${ }^{13}$ The base case was that the Han and minority candidates had equally desirable or equally undesirable characteristics. For example, both were educated locally or both were educated out of province or both had just one previous job or both had two previous jobs.

${ }^{14}$ The marginal effect of each control variable in Panel-a and Panel-b sum up to the marginal effect of the same variable in Panel-c.

${ }^{15}$ Hasmath (2012a) argues that ethnic minority candidates have higher odds of being penalized during interviews due to the perception that they may not fit into the particular workplace culture. Our study does not capture discrimination in the interview phase of the job search process.

Competing interest

The IZA Journal of Migration is committed to the IZA Guiding Principles of Research Integrity. The author declares that she has observed these principles.

\footnotetext{
Acknowledgements

This study was inspired in part by Peter Kuhn and Kailing Shen's (2009) innovative use of China's Internet job boards to study the preferences on gender, age, height and beauty expressed by Chinese firms in their job ads and in part by conversations with Zahra Siddique at IZA about her dissertation work, which employed a resume audit methodology to investigate caste-basted discrimination in India's white-collar job market. I am very thankful to Rachel Connelly for her thoughtful feedback throughout the process of analyzing the data. I would also like to thank Reza Hasmath for his comments on earlier drafts of the paper and to acknowledge the valuable comments and questions about my initial findings from this journal's anonymous referee and the participants at the Conference on Ethnicity, Economy, and Society in China and the World in Beijing October 2011, the IAFFE Annual Conference in Barcelona June 2012, and the EALE Annual Conference in Bonn September 2012. I am particularly grateful for the expert research assistance provided by my undergraduate students, Sili Wang and Lei Lei, who carefully managed the application and tracking process.

Responsible editor: Amelie Constant
}

Received: 26 August 2012 Accepted: 10 December 2012

Published: 31 December 2012

\section{References}

Barabantseva E (2009) Development as localization: ethnic minorities in China's official discourse on the western development project. Critical Asian Studies 41(2):225-254

Bequelin N (2009) Behind the violence in Xinjiang. The New York Times. published online July 9, 2009. http://www. nytimes.com/2009/07/10/opinion/10iht-edbequelin.html?_r=0 (accessed August 24, 2012.)

Bertrand M, Mullainathan S (2004) Are Emily and Greg more employable than lakisha and Jamal? a field experiment on labor market discrimination. Am Econ Rev 94(4):991-1013

Bhattacharji P (2012) Uighurs and China's Xinjiang region." Council on Foreign Relations. www.cfr.org/china/uighurschinas-xinjiang-region/p16870. web log post May 29, 2012 (accessed August 24, 2012)

Booth A, Leigh A, Varganova E (2011) Does ethnic discrimination vary across minority groups? evidence from a field experiment. Oxf Bull Econ Stat 74(4):1-27 
Bursell M (2007) What's In a name? a field experiment test for the existence of ethnic discriminatio. Stockh Univ Cent Integration Stud (SULCIS) :1-28, Working Paper

Carlsson M (2010) Experimental evidence of discrimination in the hiring of first-and second-generation immigrants. Labour 24(3):263-278

Carlsson M, Rooth D-O (2007) Evidence of ethnic discrimination in the Swedish labor market using experimental data. Labour Econ 14:716-729

Ding S, Li S (2009) An Empirical Analysis of Income Inequality between a Minority and Majority in Urban China: The Case of the Ningxia Hui Autonomous Region," Global COE Hi-Stat Discussion Paper Series 022. Hitotsubashi University, pp 1-26

Fallows J (2009) No Uighurs Need Apply. The Atlantic. http://www.theatlantic.com/technology/archive/2009/07/-nouighurs-need-apply/21071/ (accessed August 25, 2012)

Guang L, Kong F (2010) Rural Prejudice and Gender Discrimination in China's Urban Job Market. In: One country, two societies: rural-urban inequality in contemporary China. Harvard University Press, Cambridge, Mass, pp 241-264

Gustaffson B, Ding S (2008) Temporary and persistent poverty among ethnic minorities and the majority in rural china. IZA Discussion Paper 3791:1-31

Gustafsson B, Li S (2003) The ethnic minority-majority income Gap in rural china during transition. Econ Dev Cult Chang 51(4):805-822

Hannum E, Xie Y (1998) Ethnic stratification in northwest china: occupational differences between Han Chinese and national minorities in Xinjiang, 1982-1990. Demography 35(3):323-333

Hasmath R (2011) From job search to hiring and promotion: the labour market experiences of ethnic minorities in Beijing. Int Labour Rev 150(1-2):189-201

Hasmath R (2012a) The Ethnic Penalty: Immigration, Education and the Labour Market. Burlington, VT and Surrey, UK: Ashgate

Hasmath R (2012b) Migration, labour and the rise of ethno-religious consciousness among uyghurs in urban Xinjiang. J Sociol :1-15

Howell A, Fan C (2011) Migration and inequality in xinjiang:a survey of Han and Uyghur migrants in Urumqi. Eurasian Geogr Econ 52(1):119-139

Information Office of the State Council of the People's Republic of China (2009) "White Paper: China's Ethnic Policy and Common Prosperity and Development of All Ethnic Groups. China.org.cn. http://www.china.org.cn/government/ whitepaper/node_7078073.htm (accessed August 24, 2012)

Kaas L, Manger C (2011) Ethnic discrimination in Germany's labour market: a field experiment. Ger Econ Rev 13(1):1-20

Kuhn P, Shen K (2009) Employers' Preferences for gender, Age, height and beauty: direct evidence. NBER working paper no. 15564

Mackerras C (2003) China's Ethnic Minorities and Globalization. London and New York, RoutledgeCurzon

Maurer-Fazio M, Hughes J, Zhang D (2007) An ocean formed from One hundred rivers: the effects of ethnicity, gender, marriage, and location on labor force participation in urban china. Feminist Econ 13(3-4):125-153

Maurer-Fazio M, Hughes J, Zhang D (2010) A comparison and decomposition of reform-era labor force participation rates of China's ethnic minorities and Han majority. Int J Manpow 31(2):138-162

NBS and SEAC. National Bureau of Statistic, P.R.C Department of Population, Social Science, and Technology Statistics and State Ethnic Affairs Commission, Department of Economic Development (2003) The Tabulation on Nationalities of 2000 Population Census of China. Ethnic Publishing House, Beijing

NBS. National Bureau of Statistics of China (2005) China Statistical Yearbooks, accessed through China Data Online to provincial statistics/ people's livelihood and worker's wage/basic statistics for people's livelihood/

Oreopoulos P, Dechief D (2011) Why do some employers prefer to interview Matthew, but not Samir? New Evidence from Toronto, Montreal, and Vancouver. Centre of Excellence for Research on Immigration and Diversity, Working Paper Series 11, no. 13, Metropolis British Columbia, pp 1-68

Pager D (2007) The Use of field experiments for studies of employment discrimination: contributions, critiques, and directions for the future. Ann Am Acad Pol Soc Sci 609(1):104-133

People's Republic of China, Ministry of Commerce (1995) Labour Law of the People's Republic of China. Adopted at the 29th Meeting of the Standing Committee of the Tenth National People's Congress on August 30, 2007 and implemented January 1, 2008. http://www.china.org.cn/living_in_china/abc/2009-07/15/content_18140508.htm (accessed August 25, 2012)

People's Republic of China (2008) Law of the People's Republic of China on Promotion of Employment." Social Law. http://www.npc.gov.cn/englishnpc/Law/2009-02/20/content_1471590.htm (accessed August 25, 2012)

Riach PA, Rich J (2002) Field experiments of discrimination in the market place. Econ J 112(483):480-518

Sautman B (2010) Scaling back minority rights? the debate about China's ethnic policies. Stanford J Int law 46(1):51-120

SEAC. State Ethnic Affairs Committee (2003) China's Yearbook of Ethnic Works 2003. Beijing

SEAC and NBS. State Ethnic Affairs Committee, Department of Economic Development and National Bureau of Statistics, P.R. C., Department of Integrated Statistics (2000) China's Ethnic Statistical Yearbook. Ethnic Publishing House, Beijing

Siddique Z (2008) Caste Based Discrimination: Evidence and Policy. IZA DP No. 3737 pp 1-44

The Economist (2011) Xinjiang: Let them shoot hoops | The Economist The Economist - World News, Politics, Economics, Business \& Finance. http://economist.com/node/21524940 (accessed August 24, 2012)

Zhao J (2008) Analysis on the Influence of Ethnicity Status on Minority Graduate Students Employment in Our Area. In: Inner Mongolia Industrial University Employment Research Report No 10

doi:10.1186/2193-9039-1-12

Cite this article as: Maurer-Fazio: Ethnic discrimination in China's internet job board labor market. IZA Journal of Migration 2012 1:12. 